\title{
Rekurencja jako narzędzie do tworzenia segmentów językowych współczesnej polszczyzny
}

\author{
Wtodzimierz Lapis i Piotr Wierzchoń \\ Institute of Linguistics, Adam Mickiewicz University \\ ul. Międzychodzka 5, 60-371 Poznań \\ \{lapisw|wierzch\}@amu.edu.pl
}

\begin{abstract}
In the present text, we discuss the phenomenon of recurrence with a special focus on the issue of its formal, mathematical description. Words as well as linguistic and extralingusitic expressions created by the means of recurrence have been described along with their subject references (denotants), the methods of their construction and record. The restrictions implied on their creation were shown in the classes defined by the areas of language: system, norm and usage. We also analysed their intonation in speech. In the description, a formalism based on the theory of sets was used (set theory, abstraction classes, n-dice theory). The examples came from a corpus of Polish.
\end{abstract}

\section{Preliminaria}

Tworzone w sposób rekurencyjny słowa i wyrażenia językowe i pozajęzykowe zostały w niniejszym artykule opisane poprzez:

- wskazanie ich odniesień przedmiotowych (denotantów),

- podanie fizycznego sposobu ich konstrukcji i zapisu,

- podanie ograniczeń stosowanych w ich konstrukcji,

- umiejscowienie ich w poszczególnych klasach wyznaczonych przez 3 obszary języka: system, normę i uzus,

- omówienie intonacji stosowanej przy ich wymowie.

\section{Podstawowe definicje}

Zacznijmy od podania definicji rekurencji (w literaturze przedmiotu określanej także mianem rekursji - literatura logiczna oraz reduplikacji - literatura językoznawcza). Rozumiemy przez nią możliwość tworzenia wyrażeń o z góry określonej strukturze, ale dowolnej długości. Co istotne, zakładamy przy tym, że owo rozszerzenie syntaktyczne musi nieść ze sobą również pokrewne rozszerzenie przedmiotowe. Celowo piszemy tu ,przedmiotowe”, a nie „syntaktyczne”, aby nie ograniczać się tym stwierdzeniem jedynie do wypowiedzi językowych, ale by obejmowało ono również szereg wypowiedzi pozajęzykowych (zob. punkt 4.1).

Nasze rozważania prowadzić będziemy:

1. w ujęciu synchronicznym, a więc ograniczonym czasem (do teraźniejszości) i przestrzenią (do obszaru stosowania języka polskiego),

2. zgodnie z postulatami ${ }^{1}$ wysuniętymi przez przedstawicieli szkoły strukturalizmu czeskiego.

\footnotetext{
${ }^{1}$ Por. Saussure 1961, Hjelmslev 1953, Apresjan 1971, Harris 1951, 1968.
} 
W ujęciu tym, na gruncie działu językoznawstwa zwanym „kulturą języka”, funkcjonują trzy obszary obiektów językowych, wyznaczone przez uzus, normę i system, przy czym odpowiednio definiujemy:

1. system językowy jako ogół elementów językowych i wzorów konstrukcyjnych (reguł) ich łączenia,

2. uzus (inaczej: zwyczaj językowy) klasa środków językowych, które są zwyczajowo, praktycznie używane; zakres owego pojęcia wyznaczyć można w oparciu o tzw. poczucie językowe (intuicyjną świadomość językowa) określonego, idealnego użytkownika języka,

3. norma - skodyfikowany ${ }^{2}$ (na potrzeby języka literackiego, rozumianego jako język ludzi wykształconych $^{3}$ ) uzus; w jej skład wchodzą zatem środki językowe, które nie tylko są używane, ale i zaaprobowane przez użytkownika rozważanego języka na danym etapie jego rozwoju.

Między tymi obszarami zachodzą więc następujące zależności, wyznaczając tym samym pięć klas językowych: A, B, C, D i E.

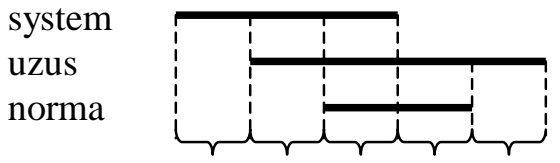

klasy
A $\quad$ B $\quad$ C $\quad$ D $\quad E$

A - klasa elementów systemu potencjalnego

B - klasa elementów uzualno-systemowych

C - klasa elementów uzualno-normatywno-systemowych

D - klasa elementów uzualno-normatywnych

E - elementy (czysto) uzualne

Schemat 1. Zależności między systemem, uzusem i normq.

Fraza - to niepusty, spójny (bez spacji) ciąg znaków alfabetu języka naturalnego (np. pas, ikj itp.).

Stowoforma ${ }^{4}$ (inaczej forma wyrazowa) - to niepusty, spójny ciąg znaków alfabetu języka naturalnego powiększonego o separator ,-"” (np. drzwi, chłopo-robotnik, aokyo itp.).

Wyrażenie językowe - to niepusty ciagg słowoform (ewentualnie wzbogacony zdefiniowanym w danym systemie znakami interpunkcyjnymi - zgodnie z regułami ich stosowania) posiadający znaczenie leksykalne ${ }^{5}$ (np. bardzo, bardzo młody, bardzo młody pracownik itp.).

Wyrażenie pozajęzykowe - to niepusty ciag słowoform nie posiadający znaczenia leksykalnego, lecz mający odniesienie przedmiotowe (np. $i$-cha-cha; puk, puk; la-la-la-la-la-la-la itp.).

Stowo - to słowoforma zbudowana bez użycia znaku separatora, posiadająca znaczenie semantyczne (leksykalne i gramatyczne lub gramatyczne). Jest więc ono szczególnym przypadkiem wyrażenia językowego (jednoelementowego, bez separatora i - rzecz jasna - znaków interpunkcyjnych).

W pracy tej jesteśmy zainteresowani tworzeniem wyrażeń pozajęzykowych, jak i językowych (jedno- i wielowyrazowych), z wyłączeniem zdaniowych (tj. tworzących zdanie) wielowyrazowych wyrażeń językowych.

\section{Notacja}

Kształt budowy wyrażeń oddawać będziemy przy pomocy tzw. wyrażeń regularnych ${ }^{6}$. Otóż, dysponując ustalonym alfabetem (liter języka polskiego powiększonym o znaki interpunkcyjne i symbole spacji i separatora „,") przyjmujemy, że wyrażeniem regularnym $W$ jest:

1. każdy $\mathrm{z}$ elementów tego alfabetu,

\footnotetext{
${ }^{2} \mathrm{~W}$ zakresie form kodyfikacji por. SO, SPP.

${ }^{3}$ Por. SJPSz; hasło: literacki.

${ }^{4}$ W kwestii szczegółowej (tj. szerszej analizy pojęć wyraz, stowoforma itp.) por. Wierzchoń 1998.

${ }^{5}$ Por. Bańczerowski et al. 1982: 198, Pogonowski 1990.

${ }^{6}$ Stosujemy pojęcie wyrażenie regularne obciążone semantycznie w obrębie lingwistyki matematycznej. Oznacza to, iż nie posługujemy się w tym miejscu pojęciem wyrażenie regularne z konotacją np. języka PERL.
} 
2. jeśli wyrażenia $\alpha, \beta \in W$, to $\alpha \beta, \alpha \cup \beta \in W$,

3. jeśli $\alpha \in W$, to $\alpha^{*} \in W$.

Tak więc wyrażenia te opisują $\mathrm{m}$. in. słowa:

1. $a, o, k$,

2. to (jako sklejenie ${ }^{7} t$ i $o$ ), $g a$ (jako sklejenie $g$ i $a$ ), tok (jako sklejenie to i $k$ ), ton i toga (ponieważ istnieje: $\operatorname{to}(n \cup g a)=\operatorname{ton} \cup$ toga, które opisują dwa słowa: ton i toga),

3. ииии (jako element zbioru $u^{*}=\{\lambda, u, u и, u и u, \ldots\}, \mathrm{tj}, u \mathrm{w}$ dowolnej krotności); wyrażenie to możemy skrótowo zapisać jako $u^{4}$. Użyte tu $\lambda$ oznacza pusty ciąg elementów.

Celem uniknięcia nieporozumień spację oznaczać będziemy symbolem „„_".

Obok $A^{*}$ oznaczajacego wyrażenie $A \mathrm{w}$ dowolnej krotności - wprowadźmy jeszcze dodatkowe niestandardowe oznaczenia:

- $A^{+}$- na oznaczenie wyrażenie $A$ w niezerowej krotności (a więc równej co najmniej 1 ,

- $A^{x}$ - na oznaczenie wyrażenie $A$ występującego w krotności co najmniej 2,

- $A^{x \geq n}$ (np.: $A^{x \geq 5}$ ) - na oznaczenie wyrażenie $A$ występującego w krotności co najmniej $n$ (tu: co najmniej 5).

Jeśli w wykładnikach tych wyrażeń po kresce pionowej ,„” dodamy pewną liczbę naturalną $m$, (np. ,|7’), to oznaczać to będzie: w krotności co najwyżej $m$ (np. w przytoczonym przykładzie: w krotności co najwyżej 7). Tak więc np. $A^{\star 15}$ oznacza $A$ w krotności od 2 do 5 . W wyniku przeprowadzonej analizy możemy wyróżnić kilka klas rozważanych tu obiektów.

\section{Wyrażenia dźwiękonaśladowcze}

\subsection{Wyrażenia czysto pozajęzykowe}

Są to wyrażenia:

opisujące muzykę - częste frekwencyjnie ${ }^{8} l a(-l a)^{*}$, wykorzystywane do odtwarzania melodii utworu muzycznego, czy też wyrażenia wykorzystywane do oddania dźwięku konkretnego instrumentu muzycznego, jak np. trą̧bi $\left(\left(\operatorname{tra}(-t a)^{x}{ }^{x}\right)^{x}\right)$ czy też puzonu $\left(\left(p a(-p a)^{x}{ }_{-}\right)^{x}\right)$;

\footnotetext{
${ }^{7}$ Inaczej: konkatenacja. Konkatenacja (łac. concatenatio 'związanie łańcuchem') jest dwuargumentową operacją, która łączy ze sobą określone znaki w tzw. rządki. Konkatenacja różni się jednak od dodawania tym, że podczas operacji dodawania nie jest istotna kolejność składników, podczas gdy konkatenacja zakłada określony, ustalony szyk. Dla przykładu, konkatenując ciągi dom- i - $u$ otrzymamy ciąg domu. Istotne jest, by w jawny sposób sprecyzować te miejsca w konkatenowanych segmentach, które stanowić mają granicę pomiędzy nimi w złożonym segmencie.

8 „Zagrałyśmy z koleżanką refleksyjną pieśń na violę da gamba i gitarę. Naliczyłam jakieś siedem, osiem natrętnych bzyków budzikowych, co jak sądzę miało znaczyć: "przynudzasz". Ktoś podłapał nawet linię melodyczną i w jednym z bardziej dramatycznych miejsc tekstu zawtórował mi na: la, la, la". www.uni.lodz.pl/puls (Puls Studenta nr 7 PoYAPAowe refleksje).

„Zbliżył się do Justyny tak, że ramieniem rękawa sukni jej dotykał; w przytłumionym głosie jego czuć było, że drżał.

- La! la! la! - zawołała.

Śpiewnie, figlarnie echo aż pod koniec firmamentu poniosło nutę:

- La, la, la, la, la!

Znowu jednak nie było to tym, o czym mówić chcieli”. Eliza Orzeszkowa Nad Niemnem.

„Tu niegdyś w wiosny poranki

Najpiękniejsza z tego sioła,

Zosia pasając baranki

Skacze i śpiewa wesoła.

La la la la.

Oleś za gołąbków parę

Chciał raz pocałować w usta;

Lecz i prośbę, i ofiarę

Wyśmiała dziewczyna pusta.

La la la la.
} 
oddające dźwięki wydawane przez:

- urządzenia techniczne, tj. np. dwutakt (dwusuw) (pyr(-pyr) $\left.\left.{ }^{\times}\right)\right)$czy też karabin maszynowy $\left(\operatorname{tra}(-\operatorname{ta})^{\times}\right)^{9}$, syrenę przemysłową $\left(\mathrm{e}^{\times}-\mathrm{a}^{\times}\left(\mathrm{e}^{\mathrm{x}}-\mathrm{a}^{\mathrm{x}}\right)\right),\left(\left(\mathrm{bru}(\mathrm{m})^{+}-\left(\mathrm{u}(\mathrm{m})^{+}\right)^{+}(-\right.\right.$ $\left.\left.\left.\mathrm{u}(\mathrm{m})^{+}\right)^{+}\right)^{+}\right)$opisujące dźwięk wydawany przez motocykl, w którym dynamicznie zmienia się wielkość dopływu paliwa

- naturę $^{10}$, np. $\operatorname{kure}^{11}\left(\mathrm{ko}(-\mathrm{ko})^{\times}\right)$, termita (beze $\left.(- \text {beze })^{\times}\right)$, wiatr $\left((\mathrm{sz})^{\times}\left(-(\mathrm{sz})^{\times}\right)^{\times}\right)$,

wyrażenia odnoszące się do fragmentów natury: np. opisujące jazdę konia / konną (pa-ta-taj(,?pa$\left.(a-t a j)^{x}\right)^{12}$ czy wykorzystywane do przywoływania kurcząt $\left(\operatorname{cip}(- \text { cip })^{\times}\right)^{13}$, itp.

Zauważmy, że niektóre z przytoczonych powyżej wyrażeń (np. opisujące wiatr, trąbkę) są „podwójnie rekurencyjne”, gdyż rekurencja odnosi się w nich do czynnika, który uległ już rekurencyjnemu rozszerzeniu, a wyrażenie opisujące borowanie jest wręcz „potrójnie rekurencyjne". Takie wielokrotne rozszerzenie rekurencyjne daje po prostu wyrażenie rekurencyjne.

\subsection{Wyrażenia parajęzykowe o rdzeniu językowym}

Mamy tu na myśli np. słowo $f r(u)^{x \geq 3}$ (o rdzeniu $f r u^{14}$ ), które choć fonicznie raczej opisuje dźwięk, to jednak służy do ekspresywnego (leksykalnego) wyrażania bezpowrotnej straty czegoś, np.: miatem kupę kasy, ale fru, cała poszła na ruletkę.

\section{Wyrażenia niedźwiękonaśladowcze (językowe)}

\subsection{Wyrażenia powstałe przez mnożenie frazy}

Do grupy tej zaliczamy wyrażenia:

a) stosowane dla wyrażenia istnienia w danym momencie takiego fragmentu wypowiedzenia, którego dokładnym znaczeniem leksykalnym nie jesteśmy zainteresowani, np.:

Józio dał wstążkę pasterce,

Antoś oddał swoje serce;

Lecz i z Józia, i z Antosia

Śmieje się pierzchliwa Zosia.

La la la la”. Adam Mickiewicz Dziady.

${ }^{9}$ Por. homofoniczne, niehosemantyczne użycie: „,...) i nawet w „Panoramie” hejnalista na wieży kościoła Mariackiego udawałby, że po reformie gra „tra ta ta” za pieniądze jak gdyby nigdy nic” www.pomorska.pl1999\styl080199\10.htm.

${ }^{10}$ Interesującym przypadkiem jest homofonia dźwięków wydawanych przez elementy techniczne i przedstawicieli świata ożywionego: np. opisujący brzęczenie muchy czy też borowanie wyraz $\left(b z^{X}\left(-z^{X}\right)^{*}\right)^{+}$. Oczywiście, mówimy w tym wypadku o zupełnie innych wyrazach, które łączy relacja homofonii.

11 „Powinieneś się był kurkiem urodzić, śmiecie pod przyzbami rozgrzebywać i "ko, ko, ko!" na czubatki wołać”. Henryk Sienkiewicz Potop.

${ }^{12}$ Por. niekonwencjonalne użycie słowoformy pa-ta-taj w poezji:

„Rzekł sternik jednoręki:

"Znam słowa te i dźwięki.

To gwara krasnoludków

Z morskiego szczepu Utków,

Ten szczep miał przeszłość sławna,

Lecz już wyginął dawno,

Zostali tylko dwaj:

Pli-plaj i Pa-ta-taj”. Jan Brzechwa Wyprawa na „Ariadnie”.

13 „Widywał nieraz na wsi gospodynię lub panienkę ze dworu, jak wyszedłszy na środek dziedzińca, rzucały poślad wołając "cip! cip!... taś! taś!..." Zlatywało się wówczas do nich ptactwo - ale jakie ptactwo? Kury, perliczki, gęsi, kaczki, indyki zwykły plebs ptasiego rodzaju, niezdolny łatać, zajęty wyłącznie żerem i sam na żer przeznaczony.” Wiktor Gomulicki Wspomnienia niebieskiego mundurka.

„Laboga, do cna przepomniałam. Józka, łap no te żółte kogutki. Cipuchny! Cip, cip, cip! A może jajków przódzi, co? A może chleba?" Władysław Reymont Chtopi.

14 „To dziwne, ale w ogóle nie czułam strachu. Podeszłam do krawędzi. Usłyszałam pytanie: „Gotowa?”. Gotowa powiedziałam. „Na 3, 2, 1 skaczemy. 3-2-1 bungee! I fru - poleciałam”. Dziennik wschodni 17 kwiecień 1998. 
- $\operatorname{bla}(-b l a)^{x}$ (np. przy omijaniu nieistotnego fragmentu czytanego komuś na głos ${ }^{15}$ ),

- ple(-ple $)^{x}$ (ironiczne przerwanie komuś dla wyrażenia informacji, że ktoś ,przynudza” lub też ,plecie głupstwa"16);

○ pla $(-p l a)^{x}$ (podobnie jak wyżej" ${ }^{17}$ );

b) stosowane dla podkreślenia chcenia, akceptacji, zachodzenia czegoś, czy też poglądu przeciwnego - poprzez danie odpowiedzi tak(,_tak) ${ }^{+}$lub nie(,_nie $)^{+}$.

\subsection{Wyrażenia powstałe przez mnożenie okolicznika przed określanym przez niego słowem}

Są to wyrażenia służące do podkreślenia wielkości czasu (np. (dawno_) ${ }^{+}$temu ${ }^{18}$, (bardzo_) ${ }^{*}$ stary ${ }^{19}$, pewnych działań (np. (bardzo_) ${ }^{*}$ mocno $^{20}$ ), pewnych okoliczności (np. (bardzo_) $\left.{ }^{*} w a z ̇ n y\right)$, nasilenia cech $(\text { bardzo_- })^{+} d u \dot{z} y^{21},\left(\text { bardzo_- }^{+} \text {gtupi, (zupetnie_- }\right)^{+}$niepoważny, $(\text {catkiem_- })^{+}$znośny ${ }^{22}$ itp.

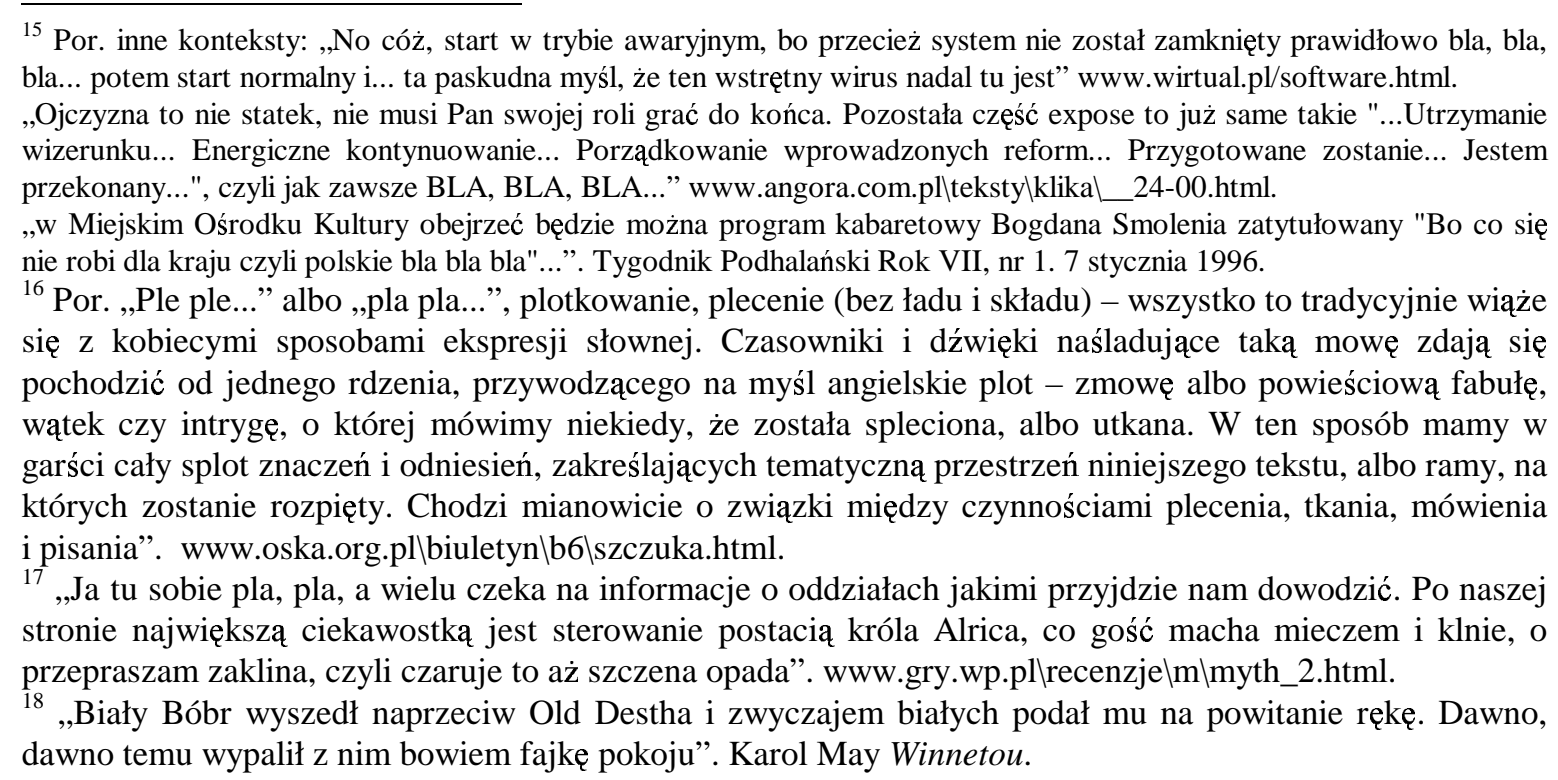

„MARYSIA

Dawno, dawno, tyle lat.

WIDMO

Skłońże ku mnie główkę, skłoń.

MARYSIA

Hańśmy stoli w dłoni dłoń -

szedł od ciebie swat.

WIDMO

Dawno, dawno, tyle lat”. Stanisław Wyspiański Wesele.

„Droga tam szła na mały wzgórek, gdzie omijane przez żyjących, w cieniu kilkunastu brzóz leżało samotne cmentarzysko cholerycznych, dawno, dawno, przed wieloma laty tu schowanych". Stefan Żeromski Popioty. „Znowu chodzić zaczął. O, jak to dawno, dawno było, kiedy te dźwięki i te słowa o jego młode, świeże, gorace serce...". Eliza Orzeszkowa Nad Niemnem.

${ }^{19}$ Por. wyszukane z korpusu zgromadzonego przez P.W. kolokacje: (bardzo, bardzo) biała, biedni, bliskiego, blisko, bogaci, boleć, brak, cieszy, ciężka, daleko, dawna, dawno, delikatne, długa, długo, dobra, dobrze, drogie, dużo, duży, dziękuję, dzikie, gorąco, gorący, kochać!, konkurencyjnej, kręta, leniwie, maluczkich, malutkie, małego, mało, miły, mocno, nie, niskim, nisko, nudzą, olbrzymia, opłacalne, piękne, pijana, pokornie, pomagać, potrzebna, pragnąłem, proszę!, przykro, realnym, rozkraczone, różne, różni, rzadko, samotny, serdecznie, słabe, smutnie, spokojna, stara, starego, szczęśliwa, tchórzliwi, trudne, trudnego, trudno, udane, umiarkowanym, ważne, wąskiej, wiele, wielkie, wolno, wstępne, wstyd, wysoko, wzruszona, zachęcająca, zahartowany, złożony, zmęczony, znajomego, życzliwy, żywą.

20 ,ZOSIA

Chciałabym kochać, ale bardzo,

ale tak bardzo, bardzo, mocno”. Stanisław Wyspiański Wesele.

21 „Gdybym miała hulajnogę,

Odbywałabym podróże 


\subsection{Wyrażenia powstałe przez mnożenie przedrostka}

Wyróżniany w tym miejscu dwa rodzaje obiektów - słowa i symbole:

a) do tworzenia słów wykorzystujemy przedrostki pra- i po-, otrzymując tym samym np. praprababcia ${ }^{23}$, popopojutrze, oddające następstwo czasowe pokoleń czy też kolejnych dni;

b) w symbolice rozmiarów odzieży stosujemy przedrostek $X$ (od extra $=$ super, tj. bardzo), na oznaczenie ubrań bardzo dużych czy też bardzo małych: ... XXXXS, XXS, XS, $M, L, X L$, $X X L, X X X L^{24}, \ldots$ (gdzie $S=$ small, tj. mały; $M=$ middle, tj. średni; $L=$ large, tj. duży).

Opisane w tym punkcie przedrostki stosuje się w maksymalnej liczbie trzech.

\subsection{Wyrażenia powstałe przez rozciągnięcie pojedynczej samogłoski}

Mamy tu na myśli np. wyrażenia $\mathrm{u}^{x \geq 3}, \mathrm{o}^{x \geq 3}, \mathrm{a}^{x \geq 3}$ (opisujące odpowiednio dźwięki: zawodu, zachwytu, zadziwienia) czy też $\mathrm{i}^{\times \geq 3}$ (wyrażające oczekiwanie rozmówcy na dokończenie wypowiedzi, w piśmie często oddawane przez: ,, $\left.-\mathrm{i} \ldots{ }_{-},{ }^{25}\right)$. W wypowiedzeniach tych znaczną rolę odgrywa właściwa ich modulacja (bez niej często mogłyby one w ogóle nie być zrozumiałe!).

\subsection{Wyrażenia powstałe przez rozciągnięcie pojedynczej głoski lub wielu głosek w wyrazie}

Z sytuacją taką mamy do czynienia w dwóch przypadkach:

a) w zastosowaniu do wykrzyknień typu: ratunku!, alarm!, hura!, w celu zwiększenia ich wyrazu emocjonalnego (przy czym efekt ten wszedł już na stałe do języka literackiego (SO) w postaci - przyjętej za poprawną - formy hurra! $)^{26}$,

Nawet bardzo, bardzo duże”. Jan Brzechwa Wiewiórka i bóbr.

${ }^{22}$ Por. podwojenie przysłówka całkiem w wyrażeniu: Całkiem, całkiem `zwrot wyrażający umiarkowana aprobatę połączoną z pewnym zdziwieniem, że taka aprobata jest należna' PSWP, t. 6. Konteksty: „Można by pogdybać, tym bardziej, że pogoda w porzednich latach była, powiedzmy ogólnie, całkiem, całkiem i w związku z tym, statystycznie rzecz biorąc... uff... będzie...”. www.pomorska.pl/1999/maj/070599/5.htm.

„Kilka dużych psów powiesiłem na pierwszych "Flintstonach" (tych sprzed 6 lat), ale z dzisiejszej

perspektywy film wydaje mi się całkiem, całkiem... Przynajmniej John Goodman był na swoim miejscu, a obsada aktorska nie była tak straszliwym nieporozumieniem".

www.gazeta.com.pl\Iso\Plus\Kultura\Film\Film-Ej\155fli.html.

${ }^{23}$ „A ponieważ cofając się jedynie o 10 pokoleń (to jest o około 200 lat w historii rodzinnej) dochodzimy do sumarycznej liczby 1022 babć i prapra...prababć, to istnieje wielkie prawdopodobieństwo statystyczne, że obyczajowa wpadka zdarzyła się w przeszłości rodzinnej każdego z nas”. Polityka 18/2000 (2243).

24 ,- Właściwie to nie wiem, czy jest to wina naszych handlowców, którzy trochę o nas zapominaja, czy producentów, którzy faktycznie nie mają dla osób o rozmiarach XXXL ciekawej propozycji - wzdycha Ryszard Bzodek”.

„Teoretyczne prace Hertza polegały głównie na porządkowaniu spuścizny Maxwella i popularyzowaniu jego teorii. Gdyby nie wysiłki Hertza, studenci fizyki musieliby uprawiać kulturystykę, żeby nosić koszulki rozmiaru XXXL ozdobione nieporadnymi rachunkami Maxwella". www.wiw.pl/fizyka/boskaczastka/Esej00000000036A84A11.htm.

25, ,- A co mi dasz za to? - dopytuje malec, nie uważając sprawy za skończona.

- Mam piłkę... Chcesz?

- Iiii... Pewnie "parcianka".

- Nie, "włosianka". Na wierzchu skóra prawdziwa.

- Eeee!... Taka to nie bardzo odskakuje”. Wiktor Gomulicki Wspomnienia niebieskiego mundurka.

„Sprężycki, na kolegę nie patrząc, zauważył tylko:

- Iiiii...

- Jak stary zacznie prawić o swoim "poecie serca", "śpiewaku Justyny", to jak Bozię kocham, język gryzę, żeby nie wybuchnąć śmiechem!”. Wiktor Gomulicki Wspomnienia niebieskiego mundurka.

${ }^{26}$ Por. rozchwianie tekstowe ortografii wyrazu hurra:

„Czasem lubię się poczuć jak niegdysiejszy myśliwy przynoszący do szałasu, czy jaskini upolowanego jelenia czy niedźwiedzia. Jaką ogromną radość sprawia mi patrzący na mnie z podziwem synowie wykrzykujący "Tato, ale wielki szczupak, jakie ma zęby, hurrra !!!"”. www.fishing.pl\rybieokolwatkilnokill.shtml.htm.

„Rozlegało się gromkie: Hip hip, hurrra! A Kazimierz Gębuś z Oleśnicy i Stefania Krzemińska z Dabrowy Oleśnickiej przećwiczyli kilka tanecznych figur przed międzypowiatowym turniejem tańca towarzyskiego". Panorama Oleśnicka Nr 10 (402), rok IX 09 - 13 marca 1999. 
b) w muzyce $-\mathrm{w}$ celu dostosowania libretta do partytury.

\subsection{Wyrazy dziecięce ${ }^{27}$}

Wiele wyrazów dziecięcych ma budowę - zdawać by się mogło - rekurencyjną. Mamy tu na myśli takie wyrazy dwusylabowe, jak. np.

- $\operatorname{papa}^{28}$ (= tata), tata, mama, dziadzia, lala,

- $\mathrm{kaka}^{29}$ (= kaczka), baba, siu-siu, koko (= kura),

- powstałe ze sklejenia pewnej sylaby z nią samą (bezpośrednio lub z pomocą łącznika). Owo powtórzenie nie jest jednak operacją rekurencyjna, gdyż wyrazy ta, tatata, tatatata, ... nie mają współodniesienia ze słowem tata (= ojciec).

\section{Wnioski i uwagi końcowe}

Język polski został wybrany jako przykładowy do omówienia przedstawionych tu zagadnień. $\mathrm{Z}$ równym powodzeniem można by rozważać omawiane tu kwestie odnośnie do innego języka naturalnego, gdyż i wtedy otrzymalibyśmy podobne wyniki.

Odnosząc przeprowadzone powyżej rozważania do opisanych na początku tego artykułu reguł z zakresu kultury języka, możemy stwierdzić, że:

a) elementami klasy A (tj. systemu potencjalnego) są te wyrażenia, w wypadku których intuicyjnie rozpoznajemy, że rekursja została przeprowadzona w nich przesadnie dużo razy, a więc te wyrażenia, które z tego powodu są za długie (np. XXXXXL),

b) za elementy klasy $\mathrm{C}$ (tj. uzualno-normatywno-systemowe) uznać możemy wyraz hurra (co wyjaśnione zostało w punkcie 5.5), jak również niektóre wyrażenia z punktów 5.2 i 5.3 (niektóre $\mathrm{z}$ tych mianowicie, w których powtarzane słowo lub przedrostek występują dwa razy, np.: praprababcia, dawno dawno temu, itp.),

c) wszystkie pozostałe opisane tu wyrażenia zaliczyć należy do klasy B (elementów uzualnosystemowych), gdyż:

- powstają one w oparciu o aparaturę opisanego tu mechanizmu (system),

- są uznane za zgodne z uzusem (bo nie spełniające tego warunku zostały już zaliczone do klasy A opisanej w podpunkcie $a$ )),

- a przy tym nie są zgodne z normą (te bowiem zaliczyliśmy już do klasy $C$ opisanej w podpunkcie $b$ )).

Na zakończenie sklasyfikujmy jeszcze sposoby oddawania rekurencji. Otóż w piśmie dokonuje się tego na cztery sposoby - poprzez: (1) jedno- lub wielokrotne bezpośrednie łączenie fraz lub też dokonywanie tego z wykorzystaniem: (2) łącznika, (3) przecinka bądź (4) spacji. Z kolei w mowie niezmiernie często wykorzystuje się do tego celu intonację, szczególnie w przypadkach przedstawionych w punktach 4.1, 4.2, 5.1, 5.4 i 5.5.

\section{Literatura}

Apresjan, Ju. D. 1971. Koncepcje i metody wspótczesnej lingwistyki (Zarys problematyki). Warszawa. Bańczerowski, J., J. Pogonowski, T. Zgółka. 1982. Wstęp do językoznawstwa. Poznań.

„Hurrrrra! Jurek Owsiak i jego Wielka Orkiestra po raz siódmy pokonali swój własny rekord. W tym roku na wielki finał - zebrali jeszcze więcej niż rok, dwa, trzy... siedem lat temu" www.pomorska.pl\1999\sty\150199\10.htm.

${ }^{27}$ W kwstii terminu por. Polański 1993: 598.

28 „Na domiar odezwała się panna Izabela, zresztą bez cienia złośliwości:

- Musi mnie papa kiedy nauczyć, jak się jada ryby nożem.

Wokulskiemu wydało się to wprost niesmaczne”. Bolesław Prus Lalka.

${ }^{29}$ Ze zwierząt pierwsza zainteresowała Jasia krowa, mówił na nią "mmmm", gdy miał 13 miesięcy, potem zaś "kwa, kwa, kla, kla" (kaczka) i "bzzzz" (pszczoła, obie w 15 miesiącu). Tatuś Jasia (czyli ja) też lubił kaczki ("kaka" w 14 miesiącu), ale jeszcze bardziej pieski ("ha" w 10 miesiącu) i kotki ("ma" w 12)". www.gazeta.com.pl/Iso/Plus/Obcasy/Dzieci/Wychowanie/081obc.html. 
Bień, J.S., Z. Saloni. 1982. Pojęcie wyrazu morfologicznego i jego zastosowanie do opisu fleksji polskiej. Prace Filologiczne, vol. XXXI. 31-45.

Bogusławski, A. 1959. O zasadach analizy morfologicznej. Biuletyn Polskiego Towarzystwa Językoznawczego, vol. 18, str. 87-96.

Bogusławski, A. 1976. Segmenty, operacje, kategorie a morfologia imienia polskiego. [w:] R. Laskowski (red.) 1976, str. 7-42.

Bolc, L. (red.) 1973. Zastosowanie maszyn matematycznych do badań nad językiem naturalnym. Warszawa.

Dunaj, B. 1979. Zarys morfologii wspótczesnej polszczyzny. Kraków.

Grzegorczykowa, R., Puzynina J. 1997. Stowotwórstwo wspótczesnego języka polskiego. Rzeczowniki sufiksalne rodzime. Warszawa.

Harris, Z. S. 1951. Methods in Structural Linguistics. Chicago.

Harris, Z. S. 1968. Mathematical Structures of Language. New York - London.

Hjelmslev, L. 1953. Prolegomena to the Theory of Language. Baltimore.

Kijewska, E. 1973. Przykład automatycznej analizy słownikowo-morfologicznej izolowanej formy rzeczownikowej. [w:] L. Bolc (red.) 1973, str. 288-235.

Kordek, N., K. Stroński (red.) 1998. Artis linguisticae paululum. Libellum professori Georgio Bańczerowski sexagenario oblatum. Poznań.

Laskowski, R. (red.) 1976. Kategorie gramatyczne grup imiennych w języku polskim. Wrocław.

Laskowski, R. 1975. Studia nad morfologia wspótczesnego języka. Wrocław.

Marciszewski, W. (red.) 1970. Mała encyklopedia logiki. Wrocław etc.

Pogonowski, J. 1990. Założenia semantyki kombinatorycznej. [w:] J. Pogonowski i T. Zgółka (red.) 1990, str. 27-43.

Pogonowski, J., T. Zgółka (red.) 1990. Struktura logiczna rozumowań lingwistycznych. Poznań.

Polański, K. (red.) 1993. Encyklopedia językoznawstwa ogólnego. Wrocław etc.

Rasiowa, H. 1968. Wstęp do matematyki współczesnej. Warszawa.

Saussure, Ferdynad de. 1961. Kurs językoznawstwa ogólnego. Warszawa.

Semeniuk, M. 1978. Elementy lingwistyki matematycznej. Warszawa.

SO. Polański, E. (red.) 1999. Nowy stownik ortograficzny PWN z zasadami pisowni i interpunkcji. Warszawa.

SPP. Markowski, A. (red.) 1999. Nowy stownik poprawnej polszczyzny PWN. Warszawa.

Szymanowska, I. 1978. Algorytmy analizy morfologicznej. Warszawa.

Urbańczyk, S. (red.). 1994. Encyklopedia języka polskiego. Wrocław etc.

Wierzbowski, L. 1973. Podzielność morfologiczna wyrazów w automatycznej analizie i syntezie tekstu polskiego. [w:] L. Bolc (red.) 1973, str. 211-219.

Wierzchoń, P. 1998. Wyraz (najmniejsza jednostka sporna). [w:] N. Kordek, K. Stroński (red.) 1998, str. 127-170. 